\title{
O CORPO DO CANTOR: ALONGAR, RELAXAR OU AQUECER?
}

\author{
The singer's body: stretch, relax or warm-up?
}

\author{
Enio Lopes Mello (1), Marta Assumpção de Andrada e Silva ${ }^{(2)}$
}

\section{RESUMO}

Tema: exercícios físicos e canto. Objetivo: fazer uma reflexão a respeito da diferença entre: alongamento, relaxamento e aquecimento e seus benefícios para os cantores. Conclusão: exercícios de aquecimento e alongamento são complementares na preparação de cantores. Aquecimento previne lesões, favorece o alongamento e garante melhor vibração das pregas vocais. Alongamento auxilia na manutenção da postura e na abertura do tórax. Relaxamento é desaconselhado na preparação do canto, porque pode comprometer o controle motor. Vocalizar é um excelente exercício de aquecimento e de alongamento das pregas vocais, porém deve ser antecedido pelo aquecimento do corpo, com ênfase na musculatura extrínseca e intrínseca da laringe sem emissão sonora.

DESCRITORES: Corpo Humano; Voz; Exercícios de Alongamento Muscular; Relaxamento

\section{INTRODUÇÃO}

Existe um consenso entre os fonoaudiólogos, professores de canto, cantores, regentes e outros profissionais da voz, sobre a necessidade de trabalhar o corpo para melhorar a expressão vocal ${ }^{1-4}$, isto é, suavizar o ataque vocal, ampliar a projeção da voz, explorar a ressonância, dominar a coordenação pneumofonoarticulatória (CPFA), e por fim melhorar aspectos como o ritmo, a velocidade, entre outros. Porém, estes profissionais e o público de maneira geral, comumente, fazem confusão entre alongamento, relaxamento e aquecimento. Estas práticas são tidas como de suma importância para os profissionais da voz, e muitas vezes confundidas. Diante dessa proposição questiona-se: qual é especificamente a função de cada uma dessas

(1) Biólogo; Cantor Lírico; Terapeuta Corporal; Afiliado ao Programa de Estudos Pós-graduados em Fonoaudiologia da Pontifícia Universidade Católica de São Paulo; Especialista em Cadeias Musculares e Articulares pelo Institut des Chaînes musculaires et techniques Godelieve Dennys-Struyf (GDS) em Bruxelas - Bélgica; Mestre em Fonoaudiologia pela Pontifícia Universidade Católica de São Paulo.

(2) Fonoaudióloga; Professora Doutora do Programa de Estudos Pós-graduados em Fonoaudiologia da Pontifícia Universidade Católica de São Paulo; Professora Doutora da graduação em Fonoaudiologia da Faculdade de Ciências Médicas da Santa Casa de Misericórdia de São Paulo; Mestre em Fonoaudiologia e Doutora em Comunicação e Semiótica pela Pontifícia Universidade Católica de São Paulo.

Apoio financeiro: CAPES, 2006/2007. modalidades mencionadas na preparação dos cantores? Será que elas se interagem ou se excluem?

Cantar é uma ação que exige do cantor grande demanda de energia física e controle emocional. Quando praticado em forte intensidade e em notas agudas, certos ajustes no trato vocal tornam-se necessários ${ }^{2}$. Se estiver associado à movimentação corporal constituem uma sobrecarga muscular ainda maior, semelhante àquelas realizadas por atletas ${ }^{3}$. Diante disso torna-se necessário preparar o corpo para se obter expressividade no canto ${ }^{1}$.

Entretanto, algumas atividades físicas não são recomendadas aos cantores, porque aumentam a tensão na musculatura do pescoço, costas, ombros e tórax, conseqüentemente pode comprometer a qualidade da $\mathrm{voz}^{3,4}$.

Em levantamento bibliográfico constatou-se uma carência de abordagens específicas da Fonoaudiologia, a respeito da preparação corporal para os cantores. Apesar da preocupação constante. Grande parte das recomendações é baseada em referências consolidadas de áreas contíguas, principalmente Educação Física e Fisioterapia, em que exercícios específicos de atividade muscular e postural dos órgãos envolvidos na fonação, bem como mudanças nos hábitos e atitudes vocais possam solucionar ou pelo menos melhorar distúrbios vocais e laríngeos ${ }^{1,3,4}$.

O objetivo deste artigo é refletir a respeito das diferenças entre alongamento, relaxamento $e$ aquecimento muscular, e seus benefícios para os cantores. 


\section{MÉTODOS}

Realizou-se pesquisa bibliográfica em sites de busca acadêmicos, livros, dissertações de mestrado e artigos em periódicos, publicados pelo LILACS, BIREME, PUBMED e MEDLINE, dentro da área da Fonoaudiologia, Educação Física, Fisioterapia, Odontologia, Medicina e Canto, para promover uma discussão que gira em torno da questão título: "o corpo do cantor: alongar, relaxar ou aquecer?" e das questões expostas na introdução: "qual é especificamente a função de cada uma dessas modalidades na preparação dos cantores?"; Será que elas se interagem ou se excluem?

Os descritores (Keywords) utilizados foram: corpo humano; voz; exercícios de alongamento muscular; relaxamento. Não consta nos Descritores de Ciências da Saúde (DeCS), um descritor correspondente ao termo aquecimento, porém incluí-lo nesse estudo foi de suma importância. $O$ intervalo de tempo da pesquisa foi de junho de 2006 a julho de 2007.

Os resultados foram analisados conforme subdivisão por assunto. Primeiramente abordou-se os conceitos básicos da biomecânica associados aos exercícios de alongamento, relaxamento e aquecimento executados por cantores. Em seguida analisou-se a relação corpo e voz na prática fonoaudiológica e de professores de canto, aplicada a cantores.

\section{REVISÃO DA LITERATURA}

\section{Conceitos básicos da biomecânica}

Para compreender as funções musculares nas atividades alongamento, relaxamento e aquecimento torna-se necessário, antes, entender o conceito de unidade motora (UM) que é a base da biomecânica. Cada UM é formada pelo conjunto de motoneurônio alfa, seu axônio, e as fibras musculares por ele inervadas. Essa descrição cabe apenas para as fibras musculares esqueléticas ${ }^{5}$. Fibras musculares cardíacas e viscerais, não serão estudadas, pois não apresentam interesse na revisão em pauta.

Os motoneurônios são células cujo axônio ramifica-se para inervar várias fibras musculares, que tendem a estarem relativamente próximas nos músculos. Essas fibras são inervadas por apenas um motoneurônio, cujo corpo celular está situado no corno anterior da medula espinal, para os músculos do tronco e membros, e nos núcleos motores dos nervos cranianos para os músculos da face e dos órgãos fonoarticulatórios ${ }^{6,7}$, que quando estimulados desencadeiam o reflexo acústico, entre outras funções ${ }^{7}$.
As fibras musculares esqueléticas são divididas em dois grupos funcionalmente diferentes, porém, complementares ${ }^{8}$ :

- Fibras rápidas: são pálidas por apresentarem baixa vascularização, contêm poucas mitocôndrias e por isso funcionam com baixa oxigenação (metabolismo anaeróbico), apresentam contração e relaxamento rápidos, desenvolvem um amplo espectro de tensão e rapidamente apresentam fadiga; são adequadas para atividades musculares rápidas e intensas.

- Fibras lentas: vermelhas, porque têm muita vascularização, ricas em mitocôndrias, portanto funcionam em condições de boa oxigenação (metabolismo aeróbico), apresentam contração e relaxamento lentos, desenvolvem uma faixa estreita de tensão e são bastante resistentes à fadiga; são adequadas para atividades musculares prolongadas, necessárias para a manutenção da postura.

A maioria dos músculos esqueléticos é formada por uma combinação destes dois tipos de fibras, isso resulta num desempenho muscular satisfatório. Este desempenho é caracterizado pela contração muscular e pela produção de força, que geram mudanças relativas de posição de várias moléculas ou filamentos no interior do arranjo muscular, denominado deslizamento. $\mathrm{O}$ deslizamento dos filamentos é provocado por um fenômeno elétrico, conhecido como potencial de ação. O potencial de ação, por sua vez, resulta na mudança do potencial de membrana, que existe entre o interior e o exterior da célula muscular ${ }^{9}$.

Quando um impulso chega até a placa motora, ele se propaga pela fibra em uma onda contrátil, que dá lugar a uma breve contração, seguida de rápido relaxamento. Esse processo tem duração, desde milésimos de segundos (mseg.), até 0,2 segundo, dependendo do tipo de fibra (rápida ou lenta).

Durante a contração, um minúsculo potencial elétrico é gerado com duração de um até quatro mseg. que se dissipa pêlo tecido circunvizinhos. Como nem todas as fibras da UM se contraem exatamente ao mesmo tempo, algumas apresentam retardo de poucos mseg. O potencial que se desenvolve na contração de uma UM se prolonga de cinco a doze mseg. O resultado dessa contração é uma descarga elétrica com duração média de nove mseg e uma amplitude total medida em microvolts $(\mathrm{mV})$ com eletrodos de agulha ${ }^{8,9}$.

Ressalta-se que músculo é o único tecido biológico capaz de desenvolver tensão ativamente e que as propriedades de extensibilidade e elasticidade são comuns a muitos tecidos biológicos. A extensibilidade é a capacidade de ser estirado (alongado) ou de aumentar o comprimento. E a elasticidade é a 
capacidade de voltar ao comprimento normal após um estiramento. Quando um tecido muscular é estirado e a sua elasticidade retorna-o ao cumprimento normal, promove uma transmissão uniforme da tensão do músculo sobre o osso ${ }^{8}$.

$\mathrm{Na}$ execução de exercícios de alongamento, as informações proprioceptivas dos movimentos de extensibilidade e elasticidade dos músculos são necessárias, para que, o Sistema Nervoso Central (SNC) componha o que se denomina via somestésica, entendida como sensibilidade somática. Trata-se do ramo aferente responsável pelo senso de posição de um segmento em relação ao próprio corpo e cinestesia, isto é, o senso de velocidade de direção do deslocamento desse segmento corpóreo. Estas funções são garantidas pelos receptores articulares dos órgãos tendinosos de Golgi e dos receptores dos fusos musculares que dentre outras, são responsáveis pelo controle de alongamento e relaxamento dos músculos.

O estudo dos receptores, na prática do canto, deve voltar seu olhar para o controle de motricidade dos órgãos fono-articulatórios (OFA), dada a complexidade de sua movimentação e a grande presença de inervação somestésica ${ }^{7}$.

Após esta breve revisão de conceitos básicos da biomecânica, segue uma reflexão sobre os conceitos específicos do alongamento, relaxamento e aquecimento muscular.

\section{Alongamento}

Ao alongar um músculo interfere-se no reflexo miotático, que tem como função primária proteger a estrutura muscular. Os fusos musculares são os receptores que controlam o comprimento muscular, e que, por estarem juntos e paralelos às fibras musculares são alongados em conjunto com elas. Isso causa alterações mecânicas, que estimulam as terminações primárias e secundárias dos receptores. As estimulações causam descargas, que ao chegarem à medula, são interpretadas e podem gerar, desde uma simples resposta miotática, até complexos ajustes motores ${ }^{10}$.

Para que as pregas vocais fiquem tensionadas e alongadas, durante a produção de sons agudos, ocorrem alguns ajustes na musculatura intrínseca da laringe ${ }^{2}$.

As pregas vocais, quando alongada, modifica sua forma arredondada para a de faixas estreitas, tornam-se mais firmes e rígidas nas freqüências agudas. Nessa condição, a freqüência da vibração das pregas vocais depende da massa e da tensão efetiva da parte vibratória da prega vocal. Outras forças relacionadas, como amortecimento das pregas, pressão subglótica e área glótica, influenciam na resistência. Essas implicações podem ser compreendidas como efeito Bernoulli ${ }^{11}$.

Neste sentido, o treinamento da elasticidade muscular incrementa a extensibilidade do músculo como um todo. Esse incremento é traduzido como força muscular. Cabe lembrar que uma das mais importantes leis do treinamento físico é a especificidade, ou seja, o treinamento de uma habilidade qualquer implica na melhora da mesma, embora todo o corpo se beneficie com as atividades ${ }^{12}$.

Para cada pessoa, existe um nível ótimo de flexibilidade a cada atividade física. $O$ excesso de mobilidade articular, além de aumentar a probabilidade de ocorrência de lesões, não melhora a performance. A intensidade faz, verdadeiramente, toda diferença no resultado, um mesmo movimento realizado pelo dobro do tempo, tem efeitos bastante diferentes no sistema músculo-esquelético ${ }^{13}$.

$\mathrm{O}$ alongamento refere-se às situações que envolvem diretamente a estrutura muscular e os tecidos moles que envolvem a articulação. As técnicas de alongamentos resultam na elasticidade e melhoria da função muscular. Enquanto a flexibilidade é resultante do trabalho de alongamento, que se reflete na amplitude do movimento articular. Alongamento da musculatura do tronco, por exemplo, contribui no posicionamento do tórax. Uma vez que, os músculos posteriores do tronco agem como um vetor de força que levam a postura da coluna para trás. Em contrapartida os músculos anteriores puxam para frente. Esse jogo de tensão constante garante aos músculos flexibilidade e resistência, ao mesmo tempo mantém a postura corporal no eixo vertical $^{14,15}$.

\section{Relaxamento}

Os receptores sensórios, conhecidos como órgãos tendinosos de Golgi (OTG) estão localizados nas junções musculotendinosas e nos tendões em ambas extremidades dos músculos. Estes respondem por meio de suas conexões neurais e tem como função inibir a elaboração de uma tensão no músculo. Isso promove relaxamento muscular, ao mesmo tempo, inibe a elaboração de tensão nos músculos antagonistas. Essa característica permite ao músculo esquelético realizar importantes funções, tais como: absorver choques, movimentar e flexibilizar as articulações, que depende diretamente das estruturas que a compõem e circundam, como ossos, cápsula articular, tendões, ligamentos, músculos, gordura e pele. Porém, essas funções somente serão garantidas quando devidamente estimulados, e quando isso acontece é caracterizado o sistema neuromuscular, dado a associação do sistema nervoso com o sistema muscular ${ }^{7,8}$. 
A habilidade de aprendizado do sistema neuromuscular, entendido como plasticidade neuronal, garante ao músculo uma condição de renovação dos seus axônios, o que lhes permitem maior poder de adaptação a novos estímulos, inclusive de relaxamento ${ }^{6,10}$.

\section{Aquecimento}

O termo aquecimento nas atividades físicas é compreendido como período em que se promove aumento, tanto na freqüência cardíaca, quanto na freqüência respiratória. Isso previne um funcionamento eficiente e seguro de seu coração, de seus vasos sangüíneos, de seus pulmões, músculos e articulações ${ }^{8,9,13}$. Recomenda-se que antes de qualquer exercício de alongamento, se faça exercícios de aquecimento. Durante exercícios mais intensos, há um aumento na atividade enzimática e conseqüentemente nas reações metabólicas associadas aos sistemas energéticos; aumentos no fluxo sanguíneo, na disponibilidade de oxigênio e redução nos tempos de contrações e de reflexos musculares. Quando bem executado, o aquecimento pode garantir flexibilidade, alívio às dores musculares e diminuir o risco de lesões, pode também, levar a um estado físico e psíquico ideal para o esforço ${ }^{5,9}$.

$\mathrm{O}$ aumento da temperatura corporal resulta nos seguintes benefícios: aumento da taxa metabólica; do fluxo sanguíneo local; da quantidade de oxigênio disponível nos músculos; da capacidade das articulações à suportar carga; da velocidade de transmissão do impulso nervoso; da velocidade e da força da contração muscular; além da diminuição do tempo de relaxamento muscular após contração; melhora a difusão do oxigênio disponível nos músculos e a coordenação motora ${ }^{8,12,13}$.

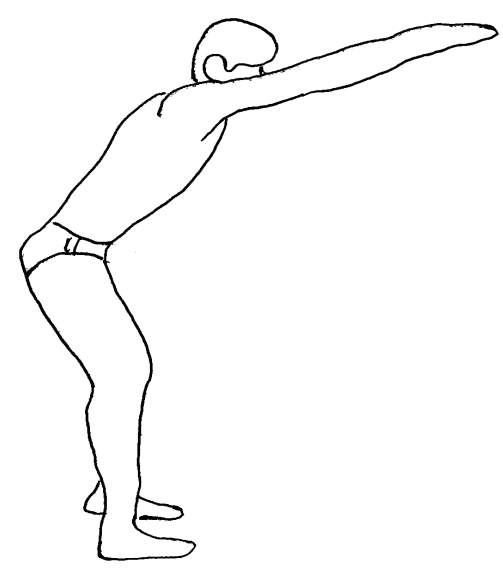

Figura 1 - Exercícios Calistênicos: pés paralelos e separados (mais ou menos $15 \mathrm{~cm}$ ); braços esticados à frente, na altura do rosto; tronco com leve inclinação para frente e joelhos desaferrolhados (levemente flexionados)
Uma seqüência de aquecimento corporal, muito interessante para cantores, pode ser iniciada com exercícios calistênicos (Figuras 1 e 2). Esses exercícios promovem rotação e flexibilização de todas as articulações. Isso garante liberdade de movimentos, desde tornozelos, joelhos, articulação coxofemoral, coluna vertebral, punhos, cotovelo, ombros, pescoço até chegar à cabeça, além de favorecer a respiração. Para ser completo o aquecimento deve ter uma fase geral e outra específica, nesta ordem. A fase geral deve movimentar grandes grupos musculares, a fim de elevar a temperatura corporal (que pode variar de $38^{\circ}$ a $39^{\circ} \mathrm{C}$ ) e preparar o corpo para atividade específica. O tempo de aquecimento varia em relação ao horário que se pratica. Para iniciantes são indicados 20 minutos e para atletas 45 minutos. De manhã quando o corpo ainda está se adaptando à movimentação, o aquecimento merece mais dedicação, do que no meio da tarde, pois a temperatura do ambiente é mais alta e o corpo já está mais aquecido. Após 45 minutos de relaxamento o corpo volta à temperatura normal, portanto novamente despreparado para o esforço. $\mathrm{O}$ aquecimento pode levar a um estado físico e psíquico ideal para o esforço ${ }^{13,14}$.

\section{Corpo e voz cantada na visão da Fonoaudiologia e do Canto}

Constatou-se nas leituras, dentro da Fonoaudiologia e do Canto, a relevância dada à condição física, como agente facilitador e/ou determinante, para a produção da voz do cantor.

Segundo alguns autores ${ }^{14-18}$, a associação de atividade física concomitante aos exercícios de treinamento da voz (aula de canto, ensaio de coral, etc.)

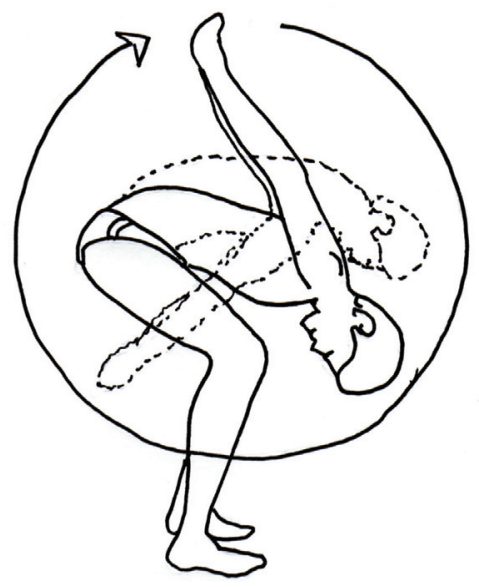

Figura 2 - Inicia-se os movimentos de braços balançando suavemente (para frente $\Leftrightarrow$ para trás, para baixo $\Leftrightarrow$ para cima), simultaneamente faz-se flexão de tronco com enrolamento da cervical (repetir 5 vezes) 
podem debelar problemas de tensão nas áreas do corpo, tais como, enrijecimento da mandíbula, tensão no pescoço e nos ombros, má postura, falta de resistência respiratória, etc.

Sabe-se que a preparação física do cantor é um recurso importante para a manutenção da saúde vocal e do corpo como um todo, e os estudos dos repertórios musicais podem aprimorar a integração: corpo, mente e voz ${ }^{14,15}$.

Nesse sentido, reflete-se que o indivíduo deve ser considerado na sua totalidade, para que possa realmente beneficiar-se da utilização das técnicas corporais e vocais como recursos facilitadores para sua voz ${ }^{17,18}$. Os ajustes na musculatura interferem no nível de tensão das pregas vocais e pode diferir em casos de cantores profissionais ou amadores, segundo a demanda e o controle técnico ${ }^{19}$.

Torna-se, portanto, imprescindível a reorganização do movimento, por meio do refinamento da biomecânica. Esse refinamento desempenha um importante papel na elaboração da voz, uma vez que tem seu princípio unificador no corpo humano e na dinâmica da adaptação do movimento ${ }^{17}$.

A relação corpo e voz, dentro da Fonoaudiologia ${ }^{2,3,4,16}$, apresenta um olhar que basicamente se preocupa em eliminar tensões, arrumar posturas, dentro de um modelo tido como ideal. Porém nem sempre as recomendações visam um encadeamento de respostas motoras ${ }^{18}$, ou seja, nem sempre a especificidade é tomada como referência, portanto, o controle das respostas pode ser desconhecido.

Estudos fisiológicos realizados por fonoaudiólogas ${ }^{3,20}$ demonstraram que o aquecimento e o desaquecimento muscular corporal, associados ao aquecimento e desaquecimento vocal são de grande importância para o condicionamento vocal. Essa constatação identifica a voz como resultante de um movimento do corpo todo. O preparo corporal preconiza uma produção vocal equilibrada. Esse equilíbrio vocal pode ser obtido por meio de uma série de técnicas que envolvem movimentos corporais globais ou específicos sobre a região do esqueleto laríngeo.

Nesse sentido cantar é uma resposta da interação do corpo inteiro que envolve a coordenação e a dinâmica dos músculos ${ }^{21}$. É uma ação que deve ser coordenada. A coordenação da musculatura intrínseca da laringe está atrelada à coordenação pneumofonoarticulatória, que está associada à coordenação motora do corpo todo. Outrossim, reflete-se que para a elaboração da voz, o corpo deve estar livre das tensões indesejadas, porém não significa estar com a musculatura relaxada, mas sim com o tônus muscular adequado para o gesto ${ }^{20}$. Nesse sentido, a correlação entre o equilíbrio psíquico e funcionamento físico, pode ter significante resultado na qualidade vocal ${ }^{22}$.

O canto é uma atividade que demanda preparo físico e emocional, portanto, torna-se necessário um treinamento adequado para se adquirir controle e propriocepção da fonação, bem como equilíbrio corporal. Isso denota a saúde do cantor, tanto vocal como corporal ${ }^{23-26}$. Certamente a postura poderá influenciar no conforto físico, e, conseqüentemente, no resultado vocal do indivíduo, uma vez que desvios posturais possibilitam distúrbios da voz, como fendas glóticas, nódulos, entre outros ${ }^{25}$.

Observa-se nos vários exemplos acima citados, ainda que importante, pouco se tem publicado a respeito da função de cada modalidade empregada na preparação física de cantores, de modo esclarecedor e que possa ser traduzido em benefícios diretos. Nota-se que existe grande preocupação e uma demanda de trabalhos corporais específicos para cantores. Por conta disto, muitas vezes as recomendações de atividades físicas são generalizadas. Tem-se a impressão de que qualquer exercício serve, para a preparação dos cantores, o importante é que se faça algo. Essa atitude desconsidera que algumas modalidades podem ser prejudiciais para cantores, como, por exemplo, o relaxamento antes de cantar, como veremos mais adiante.

Conforme revisto anteriormente, as unidades motoras recrutadas nos alongamentos musculares podem aumentar o potencial de resistência e elasticidade, quando praticadas com regularidade ${ }^{7,8}$. As respostas motoras nos alongamentos criam condições, que podem estabelecer equalização das tensões musculares sobre os ossos; elasticidade e comprimento dos músculos; organização da postura; elaboração do gesto e propriocepção ${ }^{5,17}$.

$\mathrm{Na}$ atividade física direcionada ao cantor, o alongamento deverá repercutir diretamente sobre a extensibilidade do grupo muscular envolvido no canto. Deve-se trabalhar os músculos envolvidos na produção vocal, quer sejam, músculos intrínsecos e extrínsecos da laringe, bem como os músculos do corpo todo ${ }^{1,15,17}$.

Um músculo quando estimulado aciona um segundo músculo, este por sua vez um terceiro e assim por diante. Esse é o principio básico da noção de cadeias musculares ${ }^{17,18}$.

$\mathrm{Na}$ cadeia antero-mediana (AM), por exemplo, ao se executar um exercício de extensão e flexão de pescoço, de modo direto provoca-se uma reação em cadeia de todos os músculos que a integram, ou seja, o músculo períneo, reto do abdome, grande peitoral (porção inferior e média), triangular do esterno, intercostais médios, subclaviculares, escaleno anterior, porção esternal do esternoclidomastóideos, hióideos (anteriores do pescoço) e 
músculos da estrutura bucal. Desse modo, não há como mobilizar um músculo sem que este provoque uma reação em outro próximo. Alongar os músculos das costas com exercício de flexão de tronco para frente e alongar os músculos anteriores (da barriga, peitoral, pescoço) com exercícios de inclinação do tronco para trás pode ter uma função de ajuste da postura, porque ocorre uma ação e reação de controle das cadeias musculares anterior e posterior ${ }^{17,18}$.

Entretanto há que se observar que, embora a melhora de uma condição implique em potencializar uma segunda, este efeito é decorrente e indireto, portanto, um trabalho corporal global ao mesmo tempo específico torna-se necessário ${ }^{10,13}$.

Nesse sentido, os vocalizes, por exemplo: são exercícios que quando praticados com pitch agudo podem alongar as pregas vocais ${ }^{2,14-16}$. Isso não significa que todos os músculos da laringe estejam alongados, mas sim que todos os músculos da laringe foram acionados durante $o$ alongamento das pregas vocais.

O alongamento da musculatura do tórax melhora a condição respiratória do cantor. $\mathrm{Na}$ inspiração ocorre uma expansão dos pulmões que empurra as costelas para fora, isto é, ocorre um aumento no diâmetro antero-posterior do tórax. Simultaneamente os escalenos fixam as duas primeiras costelas para cima. As fibras musculares anteriores do diafragma são tracionadas pelo esterno, que puxam o centro frênico para frente. Enquanto que, as fibras musculares posteriores do diafragma, por meio de suas inserções costais posteriores, puxam para baixo. Essa ação e reação em cadeia demonstram a grande importância do estabelecimento de uma mobilização e alongamento das fibras musculares do tórax, principalmente dos intercostais que são os responsáveis pela expansão do diâmetro anteroposterior ${ }^{17,27}$.

Nesse sentido é fundamental trabalhar o controle respiratório associados ao alongamento muscular do tórax para garantir prontidão e conscientização do papel da respiração na emissão da voz cantada. Preferencialmente opta-se pela respiração costodiafragmática, como a mais adequada para a voz.

Essas reflexões remetem a uma preocupação maior para a questão dos exercícios de relaxamentos aplicados na preparação dos cantores. Porque parece contraditório relaxar a musculatura antes de cantar, o que se necessita é justamente o contrário. Para o canto, necessita-se de tônus muscular, de propriocepção, de presença de palco com a música. Muitas vezes o relaxamento muscular acarreta desprendimento e/ou abandono das sensações do corpo. Essas atitudes podem levar a uma falsa percepção e até mesmo à falta de tônus muscular. Isso pode provocar uma deficiência na resposta motora e comprometer a performance do cantor. Sabe-se que o excesso de tensão nos músculos, por exemplo, os músculos do pescoço, podem comprometer a qualidade vocal ${ }^{3,4}$. Em contrapartida sabe-se que o relaxamento muitas vezes, leva à diminuição da tensão necessária para a realização do canto ${ }^{17,25,26}$.

Parte-se do princípio, que o corpo precisa de muita prontidão e energia para a elaboração do canto, nesse sentido o relaxamento não pode ser encarado com o propósito de preparar o corpo para o canto ${ }^{20}$. O termo relaxamento nas atividades físicas direcionadas a preparação do cantor, deve ser entendido única e exclusivamente, como ausência de tensão excessiva nos músculos e nas articulações. Estar relaxado deve significar estar pronto para receber e decodificar qualquer estímulo. É estar de prontidão!

Ao movimentar um músculo, algumas moléculas de toxinas são quebradas. O acido lático, por exemplo, tem função de reforço muscular. Porém, quando se pratica um exercício com muito esforço, rápido ou a carga for muito grande, essa toxina se acumula na bainha do músculo de modo a aprisioná-lo ${ }^{5,6,9}$. Às vezes pode acontecer, um relaxamento pelo desprendimento das toxinas. Todavia, com o aumento da carga, da velocidade e da freqüência dos exercícios, obtém-se um trabalho específico, denominado endurence (aumento da resistência) ou condicionamento da musculatura envolvida ${ }^{10,11,13}$.

Freqüentemente cantores executam rotações de ombros, pescoço, braços e denominam esses exercícios como relaxamento. Ora toda atividade que implica movimento garante maior circulação sangüínea na região trabalhada, conseqüentemente promove um aquecimento, portanto o efeito sobre o músculo, que sofreu ação do movimento, denomina-se aquecimento ${ }^{27,28}$.

No corpo em repouso ou relaxado ocorre uma queda no metabolismo, isto é, a temperatura corporal mantém-se normal, próximo dos 36으. Portanto, é de suma importância que o corpo esteja aquecido para a realização de qualquer atividade física ${ }^{10,13}$. Toda atividade física dinâmica requer atenção e encadeamento de tensão muscular! Cantar é uma atividade dinâmica que deve ser considerado uma atividade física de grande esforço físico. No caso dos cantores líricos, que são "verdadeiros atletas da voz" ", o esforço é ainda maior .

Quando se pratica o desaquecimento vocal, após uma execução de canto, faz-se um relaxamento das pregas vocais e dos músculos (intrínsecos e extrínsecos da laringe). Isso promove ajustes na musculatura e na circulação sanguínea, que 
garante condição à voz falada ${ }^{2}$. Neste propósito desaquecer é relaxar, portanto aquecer não pode ser relaxar.

Pode-se ainda, utilizar a massagem digital na laringe depois de cantar, ou antes, de dormir, para promover a vasodilatação. Isso possibilita maior relaxamento noturno e garante condições para se manter a qualidade vocal no dia seguinte ${ }^{13-15}$. Novamente, observa-se uma conduta adequada para se conseguir um relaxamento. No entanto, a massagem não deve ser empregada antes de cantar, pois ela promove diminuição do tônus muscular. Se o objetivo for liberar os movimentos, para a execução do canto, recomenda-se aquecimento pela movimentação livre, a partir dos membros inferiores, superiores, tronco, pescoço e cabeça.

Pode-se entender o relaxamento, pelo prisma da psicoterapia, que considera relaxar como o ato ou efeito de diminuir o estresse, na intenção de colocar o emocional em "equilíbrio". Pode-se ainda considerar como um fator de redução de tensões mentais e ou do cansaço corporal causado pelo esforço, trabalho, etc ${ }^{11,12,18}$.

Conforme revisto, o aquecimento deve ser a primeira parte de toda atividade física, porque age principalmente sobre o sistema cardiorrespiratório que produz um aumento da temperatura corporal. Para os cantores, o aquecimento tem benefício direto na respiração, pois aumenta da taxa metabólica, o fluxo sanguíneo local e melhora a coordenação pneumofonoarticulatória ${ }^{11,12}$.

Corpo e voz bem aquecidos reduzem o potencial de lesões nas pregas vocais. Ou seja, diminui o risco de formação de fendas nas pregas vocais; garante melhor coaptação das mesmas; melhora a vibração e pode evitar o ressecamento; melhora a condição de ataque vocal, porque coordena a ação respiratória à ação muscular, uma vez que possuem a capacidade de aumentar a coordenação neuromuscular; retardar a fadiga e tornar os tecidos menos suscetíveis a danos $3,4,27,28,30$. Além disso, a concentração psíquica provocada pelo aquecimento, possibilita anulação de pensamentos prejudiciais ${ }^{10,29}$.

Assim como na musculatura do corpo, os músculos envolvidos na produção da voz, principalmente na voz cantada, também precisam de aquecimento. Não só por se tratar de uma musculatura que requer maior quantidade de sangue, mas também, porque precisam de maior prontidão para a vibração, que acontece quando o ar passa pelas pregas vocais. $\mathrm{O}$ aquecimento vocal flexibiliza a musculatura das pregas vocais, garante maior elasticidade e resistência para os diferentes ajustes de freqüência e intensidade; otimiza o fluxo de ar trans-glótico nas tomadas inspiratórias curtas e rápidas durante 0 canto ${ }^{11}$.
Os vocalizes, freqüentemente, são recomendados e executados para aquecimento vocal 3,14,15, porém deve-se ter em mente que, embora eles realmente tenham função de aquecer, não se deve executá-los sem que, antes haja uma mobilização dos músculos intrínsecos e extrínsecos da laringe sem sonorização. Em muitos casos, os vocalizes são melodias com ritmos e seqüências de acordes tão elaborados, que mais se parecem com música, propriamente dito, do que com exercícios. Portanto, deve-se iniciar o aquecimento com rotações das articulações do corpo todo, seguido de extensão e flexão do pescoço, vibração de língua, vibração labial, emissão de sons plosivos, emissão de sons fricativos, etc., para que em um segundo momento a produção sonora possa ser efetivada.

Pesquisa recente ${ }^{31}$ constatou que, embora o aquecimento vocal seja prioridade na prática do cantor lírico, ainda existe necessidade de esclarecimentos e melhor preparo dos professores canto para prevenir problemas vocais.

Considera-se que o comportamento vocal depende de como o indivíduo percebe o próprio corpo, durante a emissão de um som, e de que modo esta percepção pode acionar os aspectos físicos e psíquicos ${ }^{28,29}$. Estes aspectos definem os ajustes laríngeos necessários para cada estilo de canto ${ }^{19}$. Por conseguinte, esta visão psicocorporal pode revelar que o estado emocional alterado interfere na flexibilidade tônica do cantor ${ }^{29}$. Por exemplo: na coordenação pneumofonoarticulatória, na postura, no ataque vocal, no controle da ressonância, na projeção da voz, na expressividade, na adequação da ênfase e curva melódica. Esta flexibilidade tônica é necessária para a emissão vocal equilibrada, em suas diversas demandas interpretativas. Isso pode constituir numa nova proposta de desenvolvimento vocal ${ }^{17}$.

\section{CONSIDERAÇÕES FINAIS}

As modalidades de exercícios alongamento e aquecimento são complementares na preparação do cantor. O aquecimento corporal de cantores deve ser adotado como prática sine qua non na preparação da voz, porque previne lesões, promove flexibilidade, favorece o alongamento e garante melhor vibração das pregas vocais. O alongamento muscular garante ao cantor maior resistência e flexibilidade para execução de movimentos e manutenção da postura em extensão axial, deve ser praticado com regularidade, para que as respostas motoras estejam disponíveis no ato da execução de uma peça. Relaxamento muscular é desaconselhado na preparação do cantor, porque pode comprometer as respostas motoras. O relaxamento deve ser 
entendido como diminuição do excesso de tensão nos músculos, sem perda de tônus muscular, que pode ser obtido com exercícios de aquecimento. Vocalizar é um excelente exercício de aquecimento e de alongamento das pregas vocais, porém deve ser antecedido pelo aquecimento corporal, com ênfase no aquecimento da musculatura extrínseca e intrínseca da laringe sem emissão sonora.

\begin{abstract}
Background: physical exercises and singing. Purpose: to make a reflection on the difference among stretching, relaxation and warm-up and theirs benefits for singers. Conclusion: warm-up and stretching exercises are complementary to preparation of singers. Warm-up prevents injuries; is favorable for stretching and provides us with better vocal folds vibration. The stretching aids to maintain posture and opening the thorax. The relaxation is not advisable to prepare the singing, because it may compromise the motor control. Vocalize is an excellent exercise for warm-up and stretching as for the vocal folds, but it must come anteceded by body warm-up, with emphasis on the extrinsic and intrinsic muscles of the larynx, without sound emission.
\end{abstract}

KEYWORDS: Human Body; Voice; Muscle Stretching Exercises; Relaxation

\section{REFERÊNCIAS}

1. Andrada e Silva M. A expressividade no canto. In: Kyrillos LR. Expressividade: da teoria à prática. Rio de Janeiro: Revinter; 2005. p. 91-104.

2. Roman G, Cielo CA. Particularidades da técnica fonoterapêutica de sons hiperagudos: revisão de literatura. Rev CEFAC. 2006; 8(3):360-7.

3. Scarpel RD. Aquecimento e desaquecimento vocal no canto. [monografia] Salvador (BA): CEFAC - Saúde e Educação; 1999. 37p.

4. Behlau M, Pontes P. Higiene vocal. Cuidando da voz. Rio de Janeiro: Revinter; 2001.

5. Nóbrega JAM, Manzano GM. Revisão relacionada a alguns aspectos técnicos e fisiológico das ondas $\mathrm{F}$ e análise dos dados obtidos em um grupo de indivóduos diabéticos. Arq Neuro-Psiquiatr. 2001 Jun; 59(2A):192-7.

6. Engelhardt E, Laks J, Rozenthal M. Neuropsicologia. VII - Distúrbios da linguagem. Afasias: aspectos neuroclínicos/neuropsicológicos. Rev Bras Neurol. 1996; 32(1):21-6.

7. Carvallo RMM, Soares JC. Efeito do estímulo facilitador no limiar de reflexo acústico. Rev Bras Otorrinolaringol. 2004 Apr; 70(2):200-6.

8. Lima Silva AE, Gagliardi JFL, Lotufo RFM, Kiss MAPDM. Ajustes lineares vs quadráticos da curva de consumo de oxigênio em teste progressivo. $R$ Bras Ci Mov. 2003; 11(4):13-8.

9. Gonçalves A, Resende ES, Fernandes MLMP, Costa AM. Influência dos hormônios tireoidianos sobre o sistema cardiovascular, sistema muscular e a tolerância ao esforço: uma breve revisão. Arq Bras Cardiol. 2006 Set; 87(3):45-7.
10. Fogaça MC, Carvalho WB, Verreschi ITN. Estimulação tátil-cinestésica: uma integração entre pele e sistema endócrino?. Rev Bras Saude Matern Infant. 2006; 6(3):277-83.

11. Morales LJ, Correa MA. Como se produce la voz? Acta Otorrinolaringol Cir Cabeza Cuello. 2003; 31(Suppl2):42-3.

12. Araújo DSMS, Araújo CGS. Aptidão física, saúde e qualidade de vida relacionada à saúde em adultos. Rev Bras Med Esporte. 2000; 6(5):194-203.

13. Broaddus-Lawrence PL, Treole K, McCabe RB, Allen $R L$, Toppin $L$. The effects of preventive vocal hygiene education on the vocal hygiene habits and perceptual vocal characteristics of training singers. J Voice. 2000; 14(1):58-71.

14. Schneider SL, Sataloff RT. Voice therapy for the professional voice. Otolaryngol Clin North Am. 2007; 40(5):1133-49.

15. Sataloff RT, Heman-Ackah Y, Hawkshaw MJ. Clinical anatomy and physiology of the voice. Otolaryngol Clin North Am. 2007; 40(5):909-29.

16. Pedroso MIL. Técnicas vocais para profissionais da voz. [monografia] São Paulo (SP): CEFAC Saúde e Educação; 2002.

17. Molinari PMAO. Materialidade da voz [dissertação] São Paulo (SP): Pontifícia Universidade Católica de São Paulo; 2003.

18. Steuer FV. Clínica da expressão vocal: disfonia e fixidez [dissertação]. São Paulo (SP): Pontifícia Universidade Católica de São Paulo; 2003.

19. Zampieri SA, Behlau M, Brasil OOC. Análise de cantores de baile em estilo de canto popular e lírico: perceptivo-auditiva, acústica e da configuração laríngea. Rev Bras Otorrinolaringol. 2002; 68(3):378-86. 
20. Aydos B, Hanayama EM. Técnicas de aquecimento vocal utilizada por professores de teatro. Rev CEFAC. 2004; 6(1):83-8.

21. Pettersen V, Westgaard RH. Muscle activity in the classical singer's shoulder and neck region. Rev Logop.Phoni.Vocol. 2002; 27(4):169-78.

22. Costa $\mathrm{OH}$, Matias C. O impacto da voz na qualidade de vida da mulher idosa. Rev Bras Otorrinolaringol. 2005; 71(2):172-8.

23. Leite GCA, Assumpção R, Campiotto AR, Andrada e Silva MA. O canto nas igrejas: o estudo do uso vocal dos coralistas e não coralistas. Dist Comun. 2004; 16(2):229-39.

24. Nemr K, Amar A, Abrahão M, Leite GCA, Köeler $J$, Santos AO, Correa LAC. Análise comparativa entre avaliação fonoaudiológica perceptivo-auditiva, análise acústica e laringoscopias indiretas para avaliação vocal em população com queixa vocal. Rev Bras Otorrinolaringol. 2005; 71(1):13-7.

25. Braga A, Pederiva P. Voz e corporeidade segundo percepção de coristas. Rev Música Hodie. 2007; 7(2):43-51.
26. Andrade SR, Fontoura DR, Cielo CA. Interrelações entre fonoaudiologia e canto. Rev Música Hodie. 2007; 7(1):83-98.

27. Badaró AFV, Silva AH, Beche D. Flexibilidade versus alongamento: esclarecendo as diferenças. Rev Centro Ci Saúde. 2007; 33(1):32-6.

28. Tricoli V, Paulo AC. Efeito agudo dos exercícios de alongamento sobre o desempenho de força máxima. Rev Bras Ativ Fis Saúde. 2002; 7(1):6-13. 29. Souza HA, Godoy JRP. A psicomotricidade como coadjuvante no tratamento fisioterapêutico. Rev Univ Ci Saúde. 2005; 3(2):287-96.

30. Davini R, Nunes CV. Alterações no sistema neuromuscular decorrentes do envelhecimento e o papel do exercício físico na manutenção da força muscular em indivíduos idosos. Rev Bras Fisioter. 2003; 7(3):201-7.

31. Quintela AS, Leite ICG, Daniel RJ. Práticas de aquecimento e desaquecimento vocal de cantores líricos. HU Rev. 2008; 34(1):41-6.

RECEBIDO EM: 30/10/2007

ACEITO EM: 02/06/2008

Endereço para correspondência:

Rua Juréia, 394 ap. 161

São Paulo - SP

CEP: 04140-110

Tel: (11) 5083-0551 / (11) 9520-9502

E-mail: enio.mello@superig.com.br 